\title{
Contribution of Weight Gain and Its Association with Insulin Resistance and Dyslipidaemia in Rural Adolescents in Polycystic Ovarian Syndrome- A Prospective Cross-Sectional Study
}

\author{
Manisha M. Laddad¹, Nitin S. Kshirsagar², Gauri Shinde ${ }^{3}$ Vaishnavi S. Shivade ${ }^{4}$ \\ ${ }^{1}$ Associate Professor, Department of Obstetrics and Gynaecology, KIMS, DU, Karad, Maharashtra, India. \\ ${ }^{2}$ Professor, Department of Obstetrics and Gynaecology, KIMS, DU, Karad, Maharashtra, India. \\ ${ }^{3}$ Assistant Professor, Department of Obstetrics and Gynaecology, KIMS, DU, Karad, Maharashtra, India. \\ ${ }^{4}$ Senior Resident, Department of Obstetrics and Gynaecology, KIMS, DU, Karad, Maharashtra, India.
}

\section{ABSTRACT}

\section{BACKGROUND}

Polycystic ovarian syndrome (PCOS) is the most complex and common endocrinological disorder involving $5-11 \%$ of women in their reproductive age. This prevalence ranges from $2.2 \%$ to $26 \%$ in adult women in $18-45$ years age group. In a recent study, the prevalence of a confirmed diagnosis of PCOS in adolescents aged 10 to 19 years was $5-15 \%$, which increased to $10-22 \%$ when undiagnosed cases with documented symptoms qualifying for PCOS according to NIH (National institute of Health) criteria were included. PCOS is a complex endocrine disorder which is most common in women of reproductive age. PCOS may first present in adolescence, but the incidence of PCOS in adolescence is not known, as diagnostic criteria for PCOS in their adolescent age is still not defined. PCOS symptoms tend to overlap with normal pubertal changes making the diagnosis even more challenging. The objective is to study prevalence and symptomatology of polycystic ovary syndrome (PCOS) in adolescent girls. In adolescents with PCOS, dyslipidaemia, diabetes as well as obesity are all potent cardiovascular risk factors in their future reproductive life. It is a metabolic disorder which may not be related with obesity only, in lean PCOS also we can see its manifestations.

\section{METHODS}

It was prospective, cross sectional study carried out from April 2018 to March 2019. 85 adolescents $(10-19)$ with PCOS were enrolled in my study. In all participants enrolled in my study we measured body mass index (BMI) \& their waist/hip (W/H) ratio. In participants, their fasting glucose, as well as fasting insulin and fasting lipid profiles were measured. In our study, definition of Insulin resistance is, fasting glucose-to-insulin ratio should be $<4.5$. After blood reports, we found the relation of obesity markers with their insulin resistance status and their lipid parameters. After this, statistical analysis was done by using SPSS \& Mann Whitney U tests.

\section{RESULTS}

In my study, out of 85 PCOS adolescents, 60 adolescents had insulin resistance. We found that there was no correlation between BMI and $\mathrm{W} / \mathrm{H}$ ratio depending on their various lipid parameters. Surprisingly we observed that in participants with PCOS with insulin resistance, thei lipid profile was significantly abnormal, as compared to insulin-sensitive girls with PCOS. In the two groups, we found that total cholesterol $(\mathrm{p}=0.002)$, as well as triglycerides $(\mathrm{p}=<0.001)$ and their HDL $(\mathrm{p}=<0.001)$ difference was statistically significant but it was not statistically significant for low-density lipoprotein $(\mathrm{LDL})(\mathrm{P}=0.09)$.

\section{CONCLUSIONS}

In adolescents with PCOS, insulin resistance is responsible for dyslipidaemia, which is independent of obesity markers.

\section{KEY WORDS}

Dyslipidaemia, Adolescents, PCOS, Insulin Resistance, Insulin Sensitivity

\begin{abstract}
Corresponding Author: Dr. Manisha M. Laddad, Shri Sai Maternity Clinic, 75/A Block, Vithal Housing Society, Malkapur-415110, Karad (Dist. Satara), Maharashtra, India.

E-mail: drmanishald@gmail.com
\end{abstract}

DOI: $10.14260 /$ jemds/2019/535

Financial or Other Competing Interests: None.

How to Cite This Article:

Laddad MM, Kshirsagar NS, Shinde G, et al. Contribution of weight gain and its association with insulin resistance and dyslipidaemia in rural adolescents in polycystic ovarian syndrome- a prospective cross-sectional study. J. Evolution Med. Dent. Sci. 2019;8(31):2452-2455, DOI: 10.14260/jemds/2019/535

Submission 10-06-2019,

Peer Review 16-07-2019,

Acceptance 22-07-2019,

Published 05-08-2019. 


\section{BACKGROUND}

Polycystic ovary syndrome is also known as endocrinopathy in reproductive age, it is always associated with multiple metabolic disorders, like hyperinsulinemia, abnormal glucose intolerance, over weight and altered in lipid profile.(1,2) Insulin resistance is thought to be pathogenic factor in associations with hypertension, glucose intolerance, obesity, lipid profile abnormalities and coronary artery disease, which together called as syndrome ' $\mathrm{X}$ with multiple aetiology or complex metabolic disorder with unknown aetiology.(3)All tough, Studies done on Indian population, are limited, but all of them have suggested that its abnormalities of the insulin receptor responsible for PCOS in Indian women compared to white women having PCOS.(4) The purpose of this study was to find out association of abnormal lipid profile in PCOS adolescents in rural areas having insulin resistance.

\section{METHODS}

It's a prospective, cross sectional study done from April 2018 to March 2019 in the Department of Obstetrics and Gynaecology of Krishna institute of medical sciences Karad. After taking proper history and consent and ethical permission from institute our study was started. In my study Eighty-five adolescents were diagnosed as a PCOS according to Rotterdam ESHRE/ASRM PCOS group's revised 2003 criteria. According to it there should be any two of three criteria must present to label that case as a PCOS.(5) Rotterdam, criteria were-

a. Oligomenorrhea and / or anovulatory menstrual cycles,

b. Clinical signs like obesity or hirsutism 0r biochemical changes of hyperandrogenism in blood investigations.

c. Polycystic changes in ovaries on U.S.G. which shows more than 4-5 follicles.

In all cases we should exclude $\mathrm{CAH}$ or androgen secreting tumours. All adolescents enrolled in my study, called in fasting status and their blood was investigated for glucose, insulin as well as lipid profile levels, which includes triglycerides, total cholesterol, and high-density lipoprotein (HDL) as well as lowdensity lipoprotein (LDL) levels were estimated by using enzymatic in vitro assay kits. Insulin levels were measured by radioimmunoassay technique. A 2-hour 75 g glucose tolerance test was done in all PCOS adolescents.

\section{Exclusion Criteria}

Participants with impaired glucose tolerance test or those having type 2 diabetes.

We considered parameters, 1) body mass index 2) waist hip ratio for depiction of central obesity, and it was used to understand relationship of obesity to lipid parameters. To calculate the body mass index Height was measured in meter and weight in $\mathrm{kg}\left(\mathrm{kg} / \mathrm{m}^{2}\right)$. These 85 adolescents were then divided into three groups based on BMI according to ACOG criteria: Normal when BMI $<25 \mathrm{~kg} / \mathrm{m}^{2}$; overweight when 25 $30 \mathrm{~kg} / \mathrm{m}^{2}$; and obese when BMI $>30 \mathrm{~kg} / \mathrm{m}^{2}$. (6) After measuring waist circumference and hip circumference as per standard guidelines. Waist-to-hip ratio was calculated. In my study Waist-to-hip ratio $>0.85$ was considered abnormal, and $<0.85$ was considered normal.(7) To detect the influence of obesity on the lipoprotein profile in PCOS adolescents, in our study we compared lipid profile of PCOS adolescents, in different BMI groups and then find its relation with their waist-to-hip ratios.

Further we divide participants in two groups

1. Insulin-resistant PCOS $(\leq 4.5)$

2. Insulin-sensitive PCOS $(>4.5)$.

Later on, depending on fasting glucose/insulin ratio, and Lipid parameters we observed difference in values.

\section{Statistical Analysis}

All data in my study were expressed as mean \pm SD. Comparison among continuous variables was done by SPSS and Mann Whitney U tests. A 'P' value $<0.05$ was considered statistically significant.

\section{RESULTS}

In my study, among the 85 PCOS adolescents, there were 60 adolescents, had fasting G/I ratio $\leq 4.5$ which were classified as insulin-resistant PCOS. Which indicate that Prevalence is $70.58 \%$ in insulin resistance PCOS group. In Table one insulin resistant \& insulin sensitive PCOS and their association with different variables are shown.

\section{BMI and Lipid Profile Relation}

In my study Out Of the 85 PCOS adolescents, 33 had normal BMI, 13 were obese, 39 were overweight and. Thus only $38.82 \%$ of PCOS adolescents, shows normal BMI. After comparing all three BMI groups with their lipid profiles. It was observed that the mean total cholesterol, triglyceride, HDL and LDL cholesterol were similar in all of them. Values are shown in [Table 2]. In my study we compared value of total cholesterol, triglycerides, HDL and LDL with their waist-to-hip ratio $<0.85$ group as well as with those with ratio $>0.85$. At the end of my study we found that, in both groups the mean lipid profile values were similar. Values are shown as [Table 3]. To understand the relation of insulin resistance with lipid profile, in our study we done comparison of lipid values in the insulinresistant and with insulin-sensitive adolescents with PCOS, and abnormal dyslipidaemia was observed in insulin-resistant groups as compare to insulin-sensitive groups.

\begin{tabular}{|c|c|c|}
\hline Parameters & $\begin{array}{l}\text { Insulin Resistant } \\
(n=60) \text { Mean } \pm \text { SD }\end{array}$ & $\begin{array}{l}\text { Insulin Sensitive } \\
(n=25) \text { Mean } \pm \text { SD }\end{array}$ \\
\hline Age (years) & $16.5 \pm 3.8$ & $15.8+4.5$ \\
\hline Weight (kilograms) & $59.4 \pm 7.5$ & $57.4 \pm 7.5$ \\
\hline Height (centimeters) & $155.7 \pm 3.1$ & $155.1 \pm 3.1$ \\
\hline $\mathrm{BMI}\left(\mathrm{Kg} / \mathrm{m}^{2}\right)$ & $27.2 \pm 3$ & $24.00 \pm 2.5$ \\
\hline $\mathrm{W} / \mathrm{H}$ & $0.86 \pm 6.1$ & $0.81 \pm 7.5$ \\
\hline Fasting glucose (mg) & $100.4 \pm 9$ & $102 \pm 9.1$ \\
\hline Fasting insulin $(\mu \mathrm{U} / \mathrm{ml})$ & $34 \pm 15.6$ & $19 \pm 2.8$ \\
\hline Fasting G/l ratio & $3.01 \pm 0.7$ & $4.4 \pm 0.8$ \\
\hline \multicolumn{3}{|c|}{$\begin{array}{c}\text { Table 1. Insulin Resistant \& Insulin Sensitive PCOS and Their } \\
\text { Association with Different Variables }\end{array}$} \\
\hline
\end{tabular}

\begin{tabular}{|c|c|c|c|c|}
\hline $\begin{array}{c}\text { Mean Range Lipid } \\
\text { Parameters }\end{array}$ & $\begin{array}{c}<\mathbf{2 5} \mathbf{~ k g} / \mathbf{~ m}^{\mathbf{2}} \\
\mathbf{n = 3 3}\end{array}$ & $\begin{array}{c}\mathbf{2 5}-\mathbf{3 0} \mathbf{~ k g} / \mathbf{~ m}^{\mathbf{2}} \\
\mathbf{n = 3 9}\end{array}$ & $\begin{array}{c}\mathbf{3 0} \mathbf{~ k g} / \mathbf{m}^{\mathbf{2}} \\
\mathbf{n = 1 3}\end{array}$ & $\mathbf{P}^{*}$ \\
\hline $\begin{array}{c}\text { Total cholesterol } \\
(\mathrm{mg} / \mathrm{dl})\end{array}$ & $170.2 \pm 35.2$ & $170.3 \pm 34.9$ & $178.5 \pm 29.3$ & 1.000 \\
\hline Triglycerides (mg/dl) & $98.5 \pm 33.4$ & $106.1 \pm 43.8$ & $115.3 \pm 21.3$ & 0.395 \\
\hline HDL (mg/dl) & $43.6 \pm 8$ & $43.2 \pm 9.5$ & $40.4 \pm 5.7$ & 0.354 \\
\hline LDL (mg/dl) & $108 \pm 30.4$ & $108.5 \pm 29.4$ & $113.3 \pm 26.8$ & 0.795 \\
\hline \multicolumn{5}{|c}{ Table 2. BMI and Lipid Profile Relation } \\
\hline
\end{tabular}




\begin{tabular}{|c|c|c|c|}
\hline $\begin{array}{c}\text { Mean Range Lipid } \\
\text { Parameters }\end{array}$ & $\mathbf{< 0 . 8 5} \mathbf{n}=\mathbf{4 4}$ & $>\mathbf{0 . 8 5} \mathbf{n}=\mathbf{4 1}$ & $\mathbf{P}^{*}$ \\
\hline Total cholesterol $(\mathrm{mg} / \mathrm{dl})$ & $170 \pm 30$ & $177.08 \pm 30$ & 0.400 \\
\hline Triglycerides $(\mathrm{mg} / \mathrm{dl})$ & $105.02 \pm 44.6$ & $102.8 \pm 28$ & 0.785 \\
\hline HDL $(\mathrm{mg} / \mathrm{dl})$ & $42.9 \pm 9.9$ & $41.9 \pm 6.9$ & 0.580 \\
\hline LDL $(\mathrm{mg} / \mathrm{dl})$ & $109.2 \pm 30.0$ & $111 \pm 27.8$ & 0.800 \\
\hline \multicolumn{4}{|l|}{ Table 3. Relation of Lipid Profile with $\mathbf{W} /$ H Ratio } \\
\hline
\end{tabular}

\begin{tabular}{|c|c|c|c|}
\hline $\begin{array}{c}\text { Mean Range Lipid } \\
\text { Parameters }\end{array}$ & $\begin{array}{c}\text { Insulin Resistant n } \\
\mathbf{= 6 0}\end{array}$ & $\begin{array}{c}\text { Insulin Sensitive } \\
\mathbf{n = 2 5}\end{array}$ & $\mathbf{p}^{*}$ \\
\hline Total cholesterol $(\mathrm{mg} / \mathrm{dl})$ & $179.0 \pm 35.0$ & $153.5+19.0$ & 0.002 \\
\hline Triglycerides (mg/dl) & $115.2 \pm 35.0$ & $70 \pm 12$ & $<0.001$ \\
\hline HDL (mg/dl) & $37 \pm 5.7$ & $52 \pm 7.6$ & $<0.001$ \\
\hline LDL (mg/dl) & $113.8+30.5$ & $98 \pm 20.6$ & 0.090 \\
\hline
\end{tabular}

Table 4. Comparison of Lipid Profile Among Insulin-Resistant and Noninsulin-Resistant Polycystic Ovary Patients

Mean levels of cholesterol and triglycerides were observed higher in the insulin-resistant group; statistically significant as shown in [Table 4].

In our study it was observed that HDL levels was also significantly lower in the insulin-resistant group than that in insulin-sensitive group. But Surprisingly LDL levels all most similar in two groups. The aim of this study is to understand the association between insulin resistance with lipid profile in Rural PCOS adolescents, we observe that abnormal lipid profile in insulin resistant PCOS adolescents, which is not related with obesity. Thus Adolescents, with PCOS show insulin resistance, whether they are obese or not. We had 60/85 PCOS adolescents, having abnormal fasting G/ I ratio, means prevalence of insulin resistance was found $70.58 \%$ in our rural population.

\section{DISCUSSION}

In our study we found that the insulin-resistant group adolescents with PCOS, had significantly higher mean cholesterol and triglycerides but significantly lower HDL cholesterol levels l. There was no significant correlation found between LDL cholesterol level and insulin resistance, but in study done by Lergoet all and Robinson et all, they found high LDL levels.(8) We found high level of HDL-C, a cardio protective lipid, and; LDL-C, a risk factor for CVS, in our a study similar results were observed as observed by Legro et al.(8) in their study LDL levels are abnormally elevated in PCOS with insulinresistant states. In our study we did not found difference in lipid profile among lean or obese PCOS adolescents. There was no correlation between waist-to-hip ratio and lipid parameters were observed in our study. Same observations are found in a study done by Slowinska-Srzednicka.(9) Our results are similar with other studies. Srezednicka et al found the role of insulin responsible for lipid abnormalities in adolescents with PCOS.(9) which suggest that hyperinsulinemia, is independent of obesity,\& responsible for lipid profile disturbances in adolescent PCOS. In one more study done by Robinson et al, they found that insulin insensitivity responsible significantly beyond BMI to the lower HDL cholesterol in PCOS adolescents.(10) In their study they reach to the conclusion that polycystic ovary syndrome is associated with biochemical risk factors for early onset vascular disease that cannot be explained by obesity alone.

Indian study done by Bhattacharya et al also found correlation between the fasting $\mathrm{G} / \mathrm{I}$ ratio and the triglyceride levels. ${ }^{(11)}$ There observation findings were all most same as we found in our study. Their cut-off for fasting glucose /insulin ratio was 5 (adolescent population) like our value of 4.5 , which is used for adolescent population.(11) We have done our study on Rural PCOS adolescents, age group 10-19 at our area. And we observed that insulin resistance in adolescents PCOS, is associated with dyslipidaemia and this is not dependent on obesity alone. In our study Hyperinsulinemia has correlation with increased cardiovascular risk factors in PCOS.(12). It concludes that PCOS adolescents, require screening for insulin resistance and dyslipidaemia. Limitations in our study was, small number of sample size as well as the selection bias in including PCOS adolescents. In our study we used only fasting glucose-to-insulin ratio and not HOMA IR Index. Fasting glucoseto-insulin ratio is reliable in women without hyperglycaemia.(11,12) All our subjects were of same ethnicity where fasting glucose-to-insulin ratio is reliable. We used BMI and waist-to-hip ratio to describe obesity which may be related to dyslipidaemia. It has been observed that abdominal visceral fat in compare to subcutaneous fat correlates better with insulin resistance and other markers of PCOS.(13)

In our study We reached to the final conclusion that, high prevalence of insulin resistance in our adolescents, PCOS in rural area is i.e. $70.58 \%$. Still More research is needed to find out what is the reason for insulin resistance and dyslipidaemia in the Indian population. In South Asian immigrants mainly Britain as well as in Durban they shown high prevalence of PCOS.(14) In their study They found not only have higher prevalence and severe degree of insulin resistance but also, they tend to manifest symptoms at an earlier age than their Caucasian counterparts. They are prone for having high prevalence of diabetes and CAD. Hyperinsulinemia is triggering cause for diabetes and hypertensive diseases. Some studies proved subclinical cardiovascular disease is very high in overweight PCOS adolescents.(15) Talbott et al observed in a review that adolescents with PCOS had dyslipidaemia, and also associated with increased blood pressure, plasminogen activator inhibitor and coronary artery atherosclerotic changes in early age. An interesting observation they made was that abnormal lipid profile between PCOS cases and controls was mainly seen in women aged less than 45 years, and they observed carotid artery changes were seen in PCOS women after 45 years. This indicates that dyslipidaemia occurring at a younger age leads to atherosclerosis and cardiovascular disease later in life. Its proved that obesity is often associated with metabolic disorders, but lean PCOS adolescents were also have been found to have hyperinsulinemia and dyslipidaemia.(16) Thus we conclude that screening for dyslipidaemia in PCOS adolescents is needed in future life. We can advise some preventive measures such as diet, exercise and lifestyle modifications from adolescents age group it will definitely help in preventing long-term health risks other that infertility in these adolescents. If that fails, drug therapy with either metformin or lipid-reducing agents may have to be considered.

\section{CONCLUSIONS}

Insulin resistance is associated with dyslipidaemia in adolescent PCOS. This is independent of obesity markers like BMI and waist-to-hip ratio. The prevalence of insulin 
resistance in our PCOS adolescents is $70.58 \%$ and which leads to the conclusion that estimation of insulin resistance and dyslipidaemia is very important in Indian rural adolescent PCOS at an early age to prevent future complications of PCOS in their reproductive life.

\section{ACKNOWLEDGEMENT}

We thank all adolescents who enrolled in this study, all colleagues, all postgraduate students in the Department of OBGYN who cooperated in conducting the study and the management for encouragement. Special thanks to the HOD of OBG Department, and Medical Director for supporting and guiding us.

\section{REFERENCES}

[1] Legro RS, Finegood D, Dunaif A. A fasting glucose to insulin ratio is a useful measure of insulin sensitivity in women with polycystic ovary syndrome. J Clin Endocrinol Metab 1998;83(8):2694-8.

[2] Dokras A, Bochner M, Hollinrake E, et al. Screening women with potycystic ovarian syndrome for metabolic syndrome. Obstet Gynecol 2005;106(1):131-7.

[3] Apridohidze T, Essah PA, luorno MJ, et al. Prevalence and characteristics of the metabolic: syndrome in women with polycystic ovary syndrome. J Clin Endocrinol Metab 2005;90(4):1929-35.

[4] Norman RJ, Mahabeer S, Masters S. Ethnic differences in insulin and glucose response to glucose between white and Indian women with polycystic ovary syndrome. Fertil Steril 1995;63(1):58-62.

[5] Rotterdam ESHRE/ASRM-Sponsored PCOS Consensus Workshop Group. Revised 2003 consensus on diagnostic criteria and long-term health risks related to polycystic ovary syndrome. Fertil Steril 2004;81(1):19-25.

[6] American College of Obstetricians and Gynecologists. ACOG practice bulletin. Polycystic ovary syndrome. Numberb 41, December 2002. Int J Gynaecol Obstet 2003;80(3):335-48.
[7] Ovalle F, Azziz R. Insulin resistance, polycystic ovary syndrome and type 2 diabetes mellitus. Fertil Steril 2002;77(6):1095-105.

[8] Legro RS, Kunselman AR, Dunaif A. Prevalence and predictors of Dyslipidaemia in women with polycystic ovary syndrome. Am J Med 2001;111(8):607-13.

[9] Slowinska-Srzednicka J, Zgliczynski S, Wierzbicki M, et al. The role of hyperinsulinemia in the development of lipid disturbances in nonobese and obese women with the polycystic ovary syndrome. J Endocrinol Invest 1991;14(7):569-75.

[10] Robinson S, Henderson AD, Gelding SV, et al. Dyslipidaemia is associated with insulin resistance in women with polycystic ovaries. Clin Endocrinol (Oxf) 1996;44(3):277-84.

[11] Bhattacharya SM. Correlation between fasting glucose: Insulin ratio, serum triglycerides level, and triglyceride: high density lipoprotein-cholesterol ratio in adolescent girls with polycystic ovarian syndrome. J Obstet Gynecol India 2005;55(3):254-6.

[12] Mather KJ, Kwan F, Corenblum B. Hyperinsulinemia in polycystic ovary syndrome correlates with increased cardiovascular risk independent of obesity. Fertil Steril 2000;73(1):150-6.

[13] Raji A, Seely EW, Arky RA, et al. Body fat distribution and Insulin resistance in healthy Asian Indians and Caucasians. J Clin Endocrinol Metab 2001;86(11):536671.

[14] Balen AH, Gerard SC, Homburg R, et al. Epidemiology of polycystic ovary syndrome in polycystic ovary syndrome: a guide to clinical management. London: Taylor and Francis 2005: p. 23-31.

[15] Meyer C, McGrath BP, Teede HJ. Overweight women with PCOS have evidence of subclinical cardiovascular disease. J Clin Endocrinol Metab 2005;90(10):5711-6.

[16] Talbott EO, Zborowski JV, Sutton-Tyrell K, et al. Cardiovascular risk in women with polycystic ovary syndrome. Obstet Gynecol Clin North Am 2001;28(1):111-33. 